\title{
North Pacific - North Atlantic linkages during the Last Glacial Termination
}

Naomi Harada ${ }^{1}$, A. Timmermann ${ }^{2}$, M. Sato ${ }^{1}$, O. SekI ${ }^{3}$, Y. Nakamura ${ }^{1}$, K. Kimoto ${ }^{1}$, Y. OKazaki ${ }^{4}$, K. Nagashima ${ }^{1}$, S.A. Gorbarenko ${ }^{5}$, L. Menviel ${ }^{6}$, M.O. СhiкAmoto ${ }^{2}$ and A. Abe-Ouchi ${ }^{1,7}$

${ }^{1}$ Research Institute for Global Change, Japan Agency for Marine-Earth Science and Technology, Japan; haradan@jamstec.go.jp ${ }^{2}$ International Pacific Research Center (IPRC), University of Hawaii, USA; ${ }^{3}$ nstitute of Low Temperature Science, Hokkaido University, Japan; ${ }^{4}$ nstitute for Advanced Study, Kyushu University, Japan; ${ }^{5} \mathrm{~V}$...I' ichev Pacific Oceanological Institute, Far East Branch of Russian Academy of Science, Russia; ${ }^{6}$ Climate Change Research Centre, University of New South Wales, Australia; ${ }^{7}$ Atmosphere and Ocean Research Institute, The University of Tokyo, Japan

\section{Statistical multivariate analysis of a new compilation of alkenone-derived sea surface temperatures from the western North Pacific indicates a coherent mode of millennial-scale variability that is closely linked to the deglacial changes of the Atlantic Meridional Overturning Circulation.}

$T^{n}$ he mid- to high-latitude region of the western-central North Pacific including its marginal seas is an essential area for understanding paleoclimate change across Asia. Surface seawater conditions such as temperature (SST) and salinity (SSS) in this region play a key role in controlling the sinking branch of the Pacific Meridional Overturning Circulation. For instance, the formation of Dense Shelf Water (Martin et al. 1998) on the continental shelf of the northwestern Okhotsk Sea is affected by autumn SST (Ogi et al. 2001), SSS, and the sea-ice extent (Sakamoto et al. 2005). Sea-ice extent has a direct effect on the volume and characteristics of Okhotsk Sea Intermediate Water, a key component of the North Pacific Intermediate Water (Tally and Nagata 1995). Moreover, large-scale changes of temperature and salinity can weaken the stratification in the Bering Sea and lead to the formation of Pacific deep water, as described in Okazaki et al. (2010).

Understanding the drivers of North Pacific surface density changes during the large-scale climate transition of the last deglaciation may provide important insights into an often-overlooked branch of the global ocean conveyor belt circulation and its effect on climate and the global carbon cycle.

Here, we focus on the SST contribution to the surface density changes in the North Pacific. Despite previous efforts to synthesize compilations of deglacial SST (Kiefer and Kienast 2005), gaps still remain in our understanding of SST variations in sinking and subduction regions in the mid- to high-latitude westerncentral North Pacific. We present a new

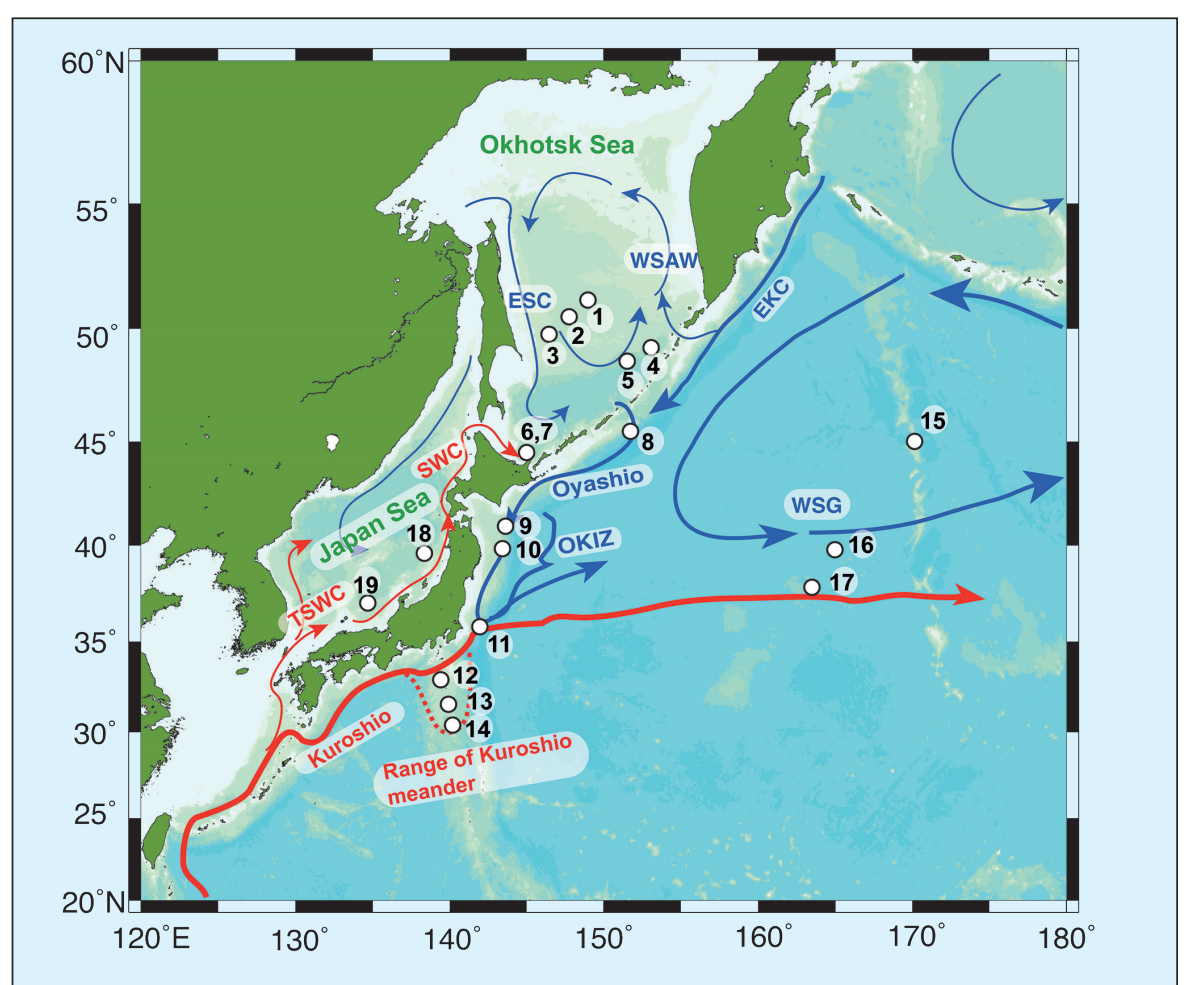

Figure 1: Sediment core locations in the western-central North Pacific and the Okhotsk and Japan Seas. Numbers indicate the coring sites as in Harada et al. (2012). Arrows show the average direction of flow of surface waters, with red and blue arrows indicating warm and cold currents, respectively. EKC, East Kamchatka Current; WSAW, Western Subarctic Water; ESC, East Sakhalin Current; SWC, Soya Warm Current; TSWC, Tsushima Warm Current; OKIZ, Oyashio-Kuroshio interfrontal zone; WSG, Western subarctic gyre. compilation of SST reconstructions for the last deglaciation derived from the $\mathrm{U}^{\mathrm{K}^{\prime}}$ -index of alkenones (Brassell et al. 1986; Prahl and Wakeham 1987) from the western-central North Pacific. We discuss how these SST responded to millennial-scale variability in the North Atlantic during the last deglaciation, including Heinrich Event 1 (H1, 17.5-14.6 ka), the Bølling-Allerød period (B-A, 14.6-12.8 ka), and the Younger Dryas (YD, 12.8-11.5 ka) through associated changes in the atmospheric circulation.

\section{Interpretation of alkenone SST}

Alkenone-SSTs were reconstructed from 19 sites in the North Pacific (Fig. 1). Alkenone-SSTs are likely to exhibit seasonal biases towards early summer to autumn in the Okhotsk Sea (Seki et al. 2007) and western-central North Pacific (Harada et al. 2004; Minoshima et al. 2007) but represent more evenly weighted near-annual mean SST in the Sea of Japan (Ishiwatari et al. 2001). In a sediment-trap study in the western North Pacific $\left(40-50^{\circ} \mathrm{N}\right)$, Harada et al. (2006) found that the season of the maximum alkenone export flux varied from the beginning of summer to late autumn, and the export period corresponded to the period when stratification had developed in the surface-subsurface layer. The light-limitation depth is also critical for alkenone producers (Harada et al. 2006). Thus calm conditions and high surface-subsurface light intensity are important for alkenone producers, and their main growing season might shift depending on when adequate conditions for their active growth occur. The high adaptability of alkenone producers might have often caused seasonal biases for alkenone-SST depending on the conditions at the coring locations.

\section{Pacific-Atlantic SST linkages}

An empirical orthogonal function (EOF) analysis was conducted for alkenone-SSTs of the interval 22-8 ka BP at 14 sites (Figs. 


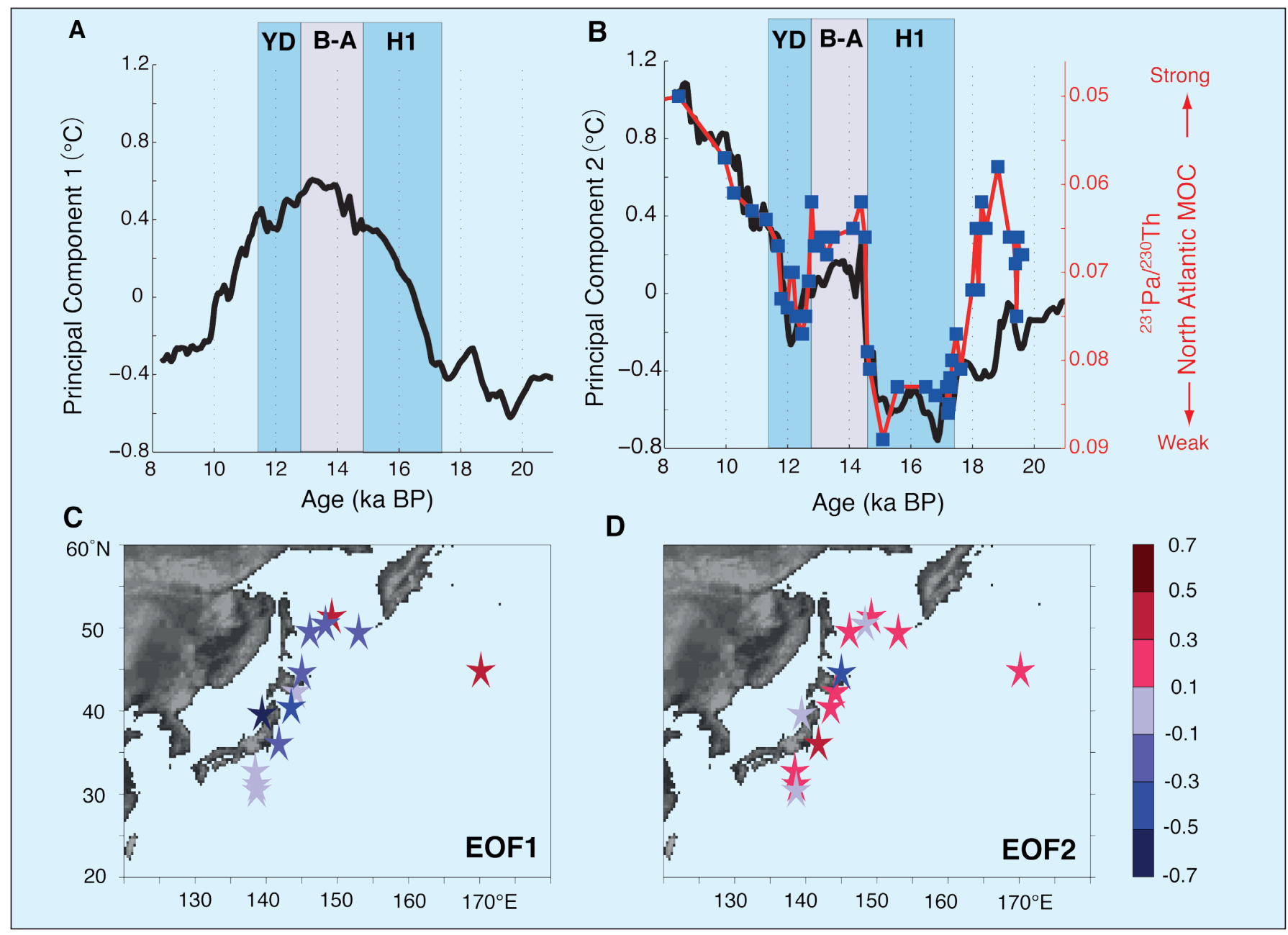

Figure 2: Empirical orthogonal function (EOF) analysis of alkenone-derived temperatures throughout 22-8 ka BP. A) First principal component [ ${ }^{\circ} \mathrm{C}$ c corresponding to EOF1 pattern. B) Second principal component $\left[{ }^{\circ} \mathrm{C}\right]$ corresponding to the EOF2 pattern, along with estimates of North Atlantic meridional overturning circulation (McManus et al. 2004). C) EOF1 and (D) EOF2 spatial patterns [unitless]. The color scale indicates the loading of the EOF pattern.

2A-2D; Harada et al. 2012) to extract the common dominant features of spatiotemporal variability from all the records.

The dominant EOF mode (EOF1) is characterized at most core sites in the northwestern Pacific by a cooling trend from 20 to $14 \mathrm{ka}$ BP and a subsequent warming trend from 14 to 8 ka BP (Fig. $2 \mathrm{~A})$. Note that the EOF contribution to the SST evolution at any core site is obtained by multiplying the principal components with the EOF pattern loading (Fig. 2C) at this site. A possible scenario is based on an independent EOF analysis from longer, but spatially more constrained alkenoneSST datasets (Harada et al. 2012), suggesting that the first EOF follows the precessional cycle of autumn insolation at $45^{\circ} \mathrm{N}$, with increased insolation during the LGM and minimum insolation around $13 \mathrm{ka} \mathrm{BP}$. These results suggest that the alkenone data track autumn temperature variations throughout the entire analysis period, and that warming during the fall season can be explained by strengthened surface stratification.

The second EOF mode (EOF2) clearly captures the main deglacial warming signal at most of the core sites as well as the millennial-scale variability associated with temperature and ocean circulation changes in the North Atlantic. It shows a distinct minimum during $\mathrm{H} 1$, a rapid increase, concomitant with the B-A transition, as well as the YD. The correspondence to a North Atlantic ventilation proxy, based on ${ }^{231} \mathrm{~Pa} /{ }^{230} \mathrm{Th}$ isotope ratios (Fig. $2 \mathrm{~B}$ ) demonstrates a clear linkage between changes in the North Atlantic overturning circulation and Pacific climate variations. The spatial EOF2 pattern is dominated by two cores (from sites 6 and 11, purple and deep red colors, respectively in Fig. 2D) having an opposite pattern. During $\mathrm{H} 1$ and according to the EOF 2 reconstruction the waters near the location of site 11 would have cooled and those near the site 6 would have warmed. This opposite temperature pattern between southern and northern sites may relate to a south-north migration of the Kuroshio/Oyashio front. This pattern may be evidence of the heat convergence toward the north by the intensified Pacific Meridional Overturning Circulation (Okazaki et al. 2010). Wind-induced transport near the western boundary affected by an intensification or shift of the Aleutian Low might be another possible factor. An intensified Aleutian Low causes also a northward migration and a strengthening of the subtropical gyre, thereby warming the waters overlying site 6 and turning heat away from the area of the site 11.

Our analysis revealed a distinct pattern of millennial-scale variability in the western North Pacific that correlates well with millennial-scale climate variations in the North Atlantic. Overall, our study suggests that multivariate data analysis of core compilations can help to identify the dominant patterns of variability and provide important insight into the driving mechanisms of variability on a range of timescales.

\section{Selected references}

Full reference list online under:

http://www.pages-igbp.org/products/newsletters/ref2012_2.pdf

Brassell SC et al. (1986) Nature 320: 129-133

Harada N et al. (2012) Deep-Sea Research II 61-64: 93-105

McManus JF et al. (2004) Nature 428: 834-837

Okazaki Y et al. (2010) Science 329: 200-204

Prahl FG, Wakeham SG (1987) Nature 330: 367-369 